\title{
ARTIGOS CIENTÍFICOS COMO RECURSO DIDÁTICO NO ENSINO SUPERIOR DE QUÍMICA
}

\author{
Luciana Massi, Gelson Ribeiro dos Santos, Jerino Queiroz Ferreira e Salete Linhares Queiroz*
}

Instituto de Química de São Carlos, Universidade de São Paulo, CP 780, 13560-970 São Carlos - SP, Brasil

Recebido em 24/8/07; aceito em 4/8/08; publicado na web em 26/1/09

\begin{abstract}
RESEARCH ARTICLES AS A DIDATIC TOOL IN UNDERGRADUATE CHEMISTRY TEACHING. Chemistry teachers increasingly use research articles in their undergraduate courses. This trend arises from current pedagogical emphasis on active learning and scientific process. In this paper, we describe some educational experiences on the use of research articles in chemistry higher education. Additionally, we present our own conclusions on the use of such methodology applied to a scientific communication course offered to undergraduate chemistry students at the University of São Paulo, Brazil.
\end{abstract}

Keywords: undergraduate education; research articles; chemistry.

\section{INTRODUÇÃO}

Os currículos dos cursos de graduação em Química enfatizam o desenvolvimento de habilidades quantitativas, como a realização de cálculos e resolução de problemas, em detrimento do desenvolvimento de habilidades qualitativas, como a comunicação e a expressão orais e escritas. ${ }^{1}$ Em movimento contrário a essa tendência, pesquisadores da área de Educação em Ciências têm destacado a necessidade da instauração de ações que favoreçam o desenvolvimento de ambos os tipos de habilidades..$^{2-4}$ Essa necessidade também é apontada nas Diretrizes Curriculares Nacionais para os Cursos de Química ${ }^{5}$ que incluem, entre as competências e habilidades necessárias aos bacharéis e licenciados, a busca de informação, comunicação e expressão. Assim, segundo as Diretrizes, ${ }^{5}$ para o bom exercício das suas atribuições profissionais, os bacharéis e licenciados em Química precisam: saber identificar e fazer busca nas fontes de informações relevantes para a Química, inclusive as disponíveis nas modalidades eletrônica e remota, que possibilitem a contínua atualização técnica, científica, humanística; ler, compreender e interpretar os textos científico-tecnológicos em idioma pátrio e estrangeiro (especialmente inglês e espanhol); saber interpretar e utilizar diferentes formas de representação (tabelas, gráficos, símbolos, expressões, etc); saber comunicar corretamente os projetos e os resultados de pesquisa na linguagem científica oral e escrita (textos, relatórios, pareceres, posters, internet, etc) em idioma pátrio e estrangeiro (especialmente inglês e espanhol).

Considerando que pesquisas relatadas na literatura apontam para a eficácia de estratégias de ensino, pautadas na utilização de artigos científicos, na promoção de algumas das habilidades anteriormente destacadas, neste trabalho temos como objetivo apresentar algumas características e possibilidades do emprego de artigos dessa natureza no ensino superior de Química. Uma vez que os artigos científicos (como recurso didático) não têm sido utilizados com frequiência no Brasil - encontramos um único exemplo descrito na literatura nacional $^{6}$ - relatamos também uma experiência realizada no Instituto de Química de São Carlos, USP, sobre sua aplicação na disciplina Comunicação e Expressão em Linguagem Científica II.

Cabe ainda esclarecer que neste trabalho não tratamos do uso de artigos científicos em cursos de pós-graduação e que consideramos como sendo de tal natureza artigos cuja organização é destacada pela divisão em seções - introdução, materiais e métodos, resultados e

*e-mail: salete@iqsc.usp.br discussão - e descrevem resultados originais de uma investigação científica, conforme define Campanario. ${ }^{2}$

\section{O USO DE ARTIGOS CIENTÍFICOS EM AMBIENTES DE ENSINO DE QUÍMICA NO NÍVEL SUPERIOR}

Algumas iniciativas sobre a utilização dos artigos científicos no ensino superior de Química, relatadas nas revistas Journal of Chemical Education, Journal of College Science Teaching, Education in Chemistry e Química Nova, foram por nós analisadas visando oferecer ao leitor sugestões sobre possibilidades de emprego do artigo científico como recurso didático.

Localizamos no Journal of Chemical Education, no período compreendido entre setembro de 1964 e agosto de 2007, 25 trabalhos $^{7-31}$ que tratam do assunto. No Journal of College Science Teaching, entre março de 1981 e agosto de 2007, localizamos 3 trabalhos..$^{32-34}$ No Education in Chemistry, entre setembro de 1996 e agosto de 2007, e na Química Nova, entre janeiro de 1978 e agosto de 2007, localizamos apenas 1 trabalho envolvendo artigos científicos em cada publicação. ${ }^{6,35}$

A análise dos trabalhos nos permitiu verificar em quais áreas da Química os artigos científicos foram empregados com maior freqüência, quais os tipos de atividades didáticas propostas e os principais objetivos almejados com a sua aplicação. A seguir, destacamos as conclusões extraídas dessa análise.

Artigos científicos: aplicação em diferentes áreas da Química e objetivos almejados com a realização de atividades didáticas

Apresentamos na Tabela 1 a classificação dos trabalhos com relação às diferentes áreas da Química nas quais as atividades didáticas foram propostas e os objetivos almejados com a realização das mesmas. Adotamos na Tabela 1 a divisão clássica: Química Geral e Inorgânica (QGI), Química Orgânica (QO), Química Analítica (QA), Físico-Química (FQ) e Bioquímica (BQ). As demais disciplinas foram classificadas como Outras $(\mathrm{O})$.

Com relação aos principais objetivos almejados com a realização das atividades pautadas na utilização dos artigos científicos, são os seguintes: ensino e aprendizagem de conteúdos específicos de disciplinas dos cursos de graduação; aperfeiçoamento de habilidades de comunicação oral e escrita em linguagem científica; familiarização com a literatura primária (localização, reconhecimento de caracterís- 
Tabela 1. Classificação dos trabalhos relacionados às diversas áreas da Química e seus principais objetivos, segundo o levantamento bibliográfico realizado nos periódicos Journal of Chemical Education, Journal of College Science Teaching, Education in Chemistry e Química Nova

\begin{tabular}{|c|c|c|c|c|c|c|}
\hline Áreas - ( $\mathrm{n}^{\mathrm{o}}$ de trabalhos) Objetivos & QGI(4) & $\mathrm{QO}(11)$ & $\mathrm{QA}(3)$ & $\mathrm{FQ}(1)$ & $\mathrm{BQ}(4)$ & $\mathrm{O}(7)$ \\
\hline $\begin{array}{l}\text { Ensino e aprendizagem de conteúdos específicos de disciplinas dos } \\
\text { cursos de graduação. }\end{array}$ & 4 & 6 & 3 & 1 & 3 & 1 \\
\hline $\begin{array}{l}\text { Aperfeiçoamento de habilidades de comunicação orais e escritas em } \\
\text { linguagem científica. }\end{array}$ & 2 & 7 & 1 & 1 & 2 & 6 \\
\hline $\begin{array}{l}\text { Familiarização com a literatura primária (localização, reconhecimento } \\
\text { de características, leitura crítica e compreensão). }\end{array}$ & 1 & 9 & 2 & 1 & 1 & 6 \\
\hline $\begin{array}{l}\text { Entendimento sobre o processo de construção do conhecimento científico } \\
\text { e familiarização com as atividades de pesquisa científica. }\end{array}$ & 2 & 5 & 1 & - & - & 1 \\
\hline
\end{tabular}

QGI = Química Geral e Inorgânica; QO = Química Orgânica; QA = Química Analítica; FQ = Físico-Química; BQ = Bioquímica; O = Outras.

ticas, leitura crítica e compreensão); entendimento sobre o processo de construção do conhecimento científico e familiarização com as atividades de pesquisa científica.

Na Tabela 1, abaixo de cada área, está citada a quantidade de trabalhos localizados que a ela se relacionam. Os números distribuídos no restante da Tabela indicam a quantidade de trabalhos que apresentaram um determinado objetivo em uma mesma área. Cabe destacar que dentre os trabalhos localizados alguns visam o alcance de mais de um dos objetivos citados. Esta é a razão pela qual o total de trabalhos apresentados na Tabela ultrapassa o número de 30 trabalhos.

A partir dos dados apresentados na Tabela 1, observamos que a maioria dos trabalhos se refere à Química Orgânica. Entre as 11 propostas apresentadas para essa área ${ }^{7-15,26,27} 4$ dizem respeito a disciplinas avançadas. Ou seja, disciplinas cursadas por alunos que já tinham familiaridade com conteúdos básicos de Química Orgânica., ${ }^{910,12,13}$ Segundo o autor de uma das propostas, ${ }^{9}$ esse aspecto favoreceu o trabalho com artigos científicos. Duas proposta se relacionam a disciplinas de caráter experimental. ${ }^{11,27}$ Em uma delas os estudantes conduzem um projeto de pesquisa sobre diferentes métodos de síntese de ésteres, chamado Ester Project e, para tanto, fazem buscas em artigos e escrevem projetos de pesquisa. ${ }^{11}$ As propostas relacionadas a essa área destacam-se por trazerem em seu bojo um objetivo que não está constantemente presente nas demais: a promoção do entendimento por parte dos alunos sobre o processo de construção do conhecimento científico e a familiarização com as atividades de pesquisa científica.

Trabalhos relacionados à Bioquímica ${ }^{16,17,33,34}$ e Química Geral e Inorgânica $^{18-21}$ também foram encontrados em número significativo. Nenhuma das propostas para a área de Bioquímica envolve disciplinas de caráter experimental e apenas 2 propostas para a área de Química Geral e Inorgânica possuem essa natureza. ${ }^{20,21}$ Na primeira, em uma disciplina de Química Inorgânica Experimental, ${ }^{20}$ os alunos reproduzem sínteses de compostos inorgânicos relatadas em artigos científicos, e na segunda, em uma disciplina de Química Geral, ${ }^{21}$ os alunos seguem o modelo de publicação do Journal of the American Chemical Society para produzir seus relatórios de laboratório. Tanto no caso da área de Bioquímica, quanto no caso da área de Química Geral e Inorgânica, grande parte das propostas foi elaborada com o objetivo principal de promover o ensino e a aprendizagem de conteúdos específicos das disciplinas.

Apenas 3 trabalhos dizem respeito à área de Química Analítica ${ }^{22,23,25}$ e somente 1 à área de Físico-Química. ${ }^{6} \mathrm{Na}$ área de Química Analítica as propostas referem-se às disciplinas Análise Instrumental ${ }^{22}$ e Análise Quantitativa. ${ }^{23,25}$ Nessas propostas os objetivos principais são o ensino e a aprendizagem de conteúdos específicos e a familiarização dos estudantes com os artigos científicos. Na área de Físico-Química a proposta refere-se a uma disciplina introdutória ao assunto e almeja, principalmente, a familiarização dos estudantes com os artigos científicos e o aperfeiçoamento de habilidades de comunicação. ${ }^{6}$
As disciplinas classificadas como Outras ${ }^{24,28-32,35}$ dividem-se em Comunicação Científica, ${ }^{24,29,30,32}$ Metodologia de Pesquisa ${ }^{31,35}$ e Organometálicos. ${ }^{28}$ Nas disciplinas de Comunicação Científica, como era de se esperar, os objetivos buscados estão relacionados, principalmente, com o aperfeiçoamento de habilidades de comunicação. Em uma das disciplinas de Metodologia de Pesquisa, ${ }^{31}$ além desse objetivo, o autor menciona a familiarização com as atividades de pesquisa, em especial a redação de projetos e relatórios científicos. Nesse contexto, os alunos também discutem a definição de pesquisa e os aspectos que a caracterizam.

\section{Artigos científicos: principais atividades didáticas desenvolvidas a partir da sua utilização}

Existe uma grande diversidade no formato das propostas de ensino analisadas, baseadas na utilização dos artigos científicos. Além das características próprias das disciplinas e dos objetivos distintos almejados com a aplicação das mesmas, discutidos anteriormente, essa diversidade é ainda devida a fatores como o tempo empregado para a realização das atividades com os artigos, que varia de um tempo restrito, como o necessário para a aplicação de um exame, ${ }^{19}$ até um período letivo inteiro ${ }^{31}$ o nível dos alunos expostos às atividades, desde calouros, ${ }^{16}$ passando por alunos do segundo ano, ${ }^{15}$ até formandos, que já escolheram um campo de especialização $;{ }^{25}$ número de alunos matriculados nas disciplinas, desde $4,{ }^{9}$ até $150^{34}$ alunos.

De maneira geral, a maioria das propostas envolve a realização das seguintes atividades: pesquisa ou busca bibliográfica dos artigos; leitura crítica e compreensão do conteúdo dos artigos; discussão do conteúdo dos artigos; elaboração de textos sobre os artigos; apresentação do conteúdo dos artigos na forma oral ou em painel.

Algumas propostas envolvendo essas atividades são discutidas a seguir: a pesquisa ou busca bibliográfica dos artigos mereceu atenção especial em 15 trabalhos. ${ }^{7,8,10,11,13-16,21,26-28,30-32}$ A preocupação com tal atividade é compreensível, uma vez que as informações contidas nessas fontes são inestimáveis para a resolução de muitos dos problemas que os alunos terão que enfrentar na carreira profissional, especialmente se optarem pela carreira acadêmica. Como a maioria dos alunos não tem familiaridade com as ferramentas de busca dos artigos, em muitas propostas é relatada a ocorrência de uma aula inicial sobre a condução da pesquisa bibliográfica, ${ }^{8,14,27}$ ou o encaminhamento dos alunos à biblioteca onde são oferecidos treinamentos. ${ }^{13}$ Em alguns casos os professores restringem a pesquisa dos artigos a alguns periódicos. Na proposta de Melhado, ${ }^{32}$ a procura é restrita aos periódicos Science, Journal of the American Chemical Society e Journal of Biological Chemistry. Em outras propostas a pesquisa bibliográfica é feita utilizando o Chemical Abstracts $(C A) .^{7,13,30}$ Uma proposta recente ${ }^{15}$ sugere uma atividade de busca, utilizando o SciFinder Scholar - um software que permite o acesso a todos os 
documentos científicos disponíveis no $C A$. Nesse caso, o professor de Química Orgânica distribuiu para cada aluno um composto que é utilizado como um auxiliar quiral. Os alunos buscaram a estrutura do composto no SciFinder Scholar, encontraram a referência de um artigo que descrevia a síntese do referido composto e localizaram um segundo artigo que descrevia uma aplicação do composto como auxiliar quiral.

Destacamos também, entre as propostas que solicitam a realização de pesquisa bibliográfica, a descrita por Rossi, ${ }^{13}$ na qual foi solicitada aos alunos matriculados em uma disciplina de Química Orgânica a escrita de um documento que relatasse o desenvolvimento de uma determinada área de pesquisa em Química. Os alunos foram orientados a localizar o artigo original no qual foram publicadas as primeiras informações sobre a área de pesquisa em foco e, em seguida, a buscar alguns trabalhos citados nesse artigo. Dessa forma, pretendiase apurar o que motivou, inicialmente, o pesquisador a executar tal trabalho, delineando o modo pelo qual o tema foi sendo desenvolvido em publicações subseqüentes e, posteriormente, se transformou em base para a pesquisa de outros cientistas.

A leitura crítica e a compreensão do conteúdo dos artigos mereceram destaque em 11 trabalhos. ${ }^{6,9,12,22-26,29,33,35}$ Embora todas as propostas exigissem a leitura do artigo científico para o desenvolvimento da atividade, destacamos aqui apenas algumas delas, nas quais a atividade de leitura teve algum tipo de acompanhamento ou orientação por parte do professor.

Na proposta de Santos, Sá e Queiroz, ${ }^{6}$ os alunos recebem a referência de um artigo científico, a incumbência de localizá-lo, e também instruções para a leitura e preparação dos resumos sobre os artigos científicos, que incluem a consideração de questões como: por que a pesquisa descrita no artigo que você leu foi realizada? qual a sua importância e quais benefícios pode trazer para a sociedade? a que conclusões chegaram os pesquisadores com base nos dados apresentados no artigo? Em uma proposta semelhante, desenvolvida por Fikes ${ }^{9}$ em disciplina de Química Orgânica Avançada, o professor optou por trabalhar com 3 artigos ao invés de adotar um livro didático. Dessa forma, para cada artigo os alunos deveriam realizar a leitura e responder às seguintes questões: qual é a questão de pesquisa desse artigo? quais foram os experimentos desenvolvidos para responder essa questão? quais são os resultados experimentais mais importantes? qual é a principal conclusão do autor? qual é a explicação alternativa para os dados experimentais?

Alguns autores conduzem a leitura do texto por meio de questões sobre o conteúdo científico do artigo. ${ }^{23,26}$ Acreditam que as questões dessa natureza ajudam o aluno a perceber os pontos mais importantes do artigo e que, ao elaborar as respostas, são revisados alguns conceitos ou descobertos termos novos, que facilitam a leitura e a compreensão do artigo científico. Na proposta de Almeida e Liotta, ${ }^{26}$ na disciplina Química Orgânica da Célula, os alunos apresentam um seminário sobre o conteúdo do artigo. Para tanto, recebem, junto com a referência do artigo, questões sobre os assuntos principais abordados que favorecem uma leitura crítica do texto. Uma proposta semelhante, que também envolve o trabalho com questões visando a compreensão do texto, foi desenvolvida por White III, ${ }^{33}$ que selecionou artigos clássicos de Bioquímica, sobre estudos a respeito da hemoglobina, para trabalhar com os alunos. Após a leitura do texto, os alunos elaboraram questões sobre os conceitos envolvidos no artigo que eram fundamentais para a sua compreensão e, além de elaborarem as questões, apresentaram ao professor as respostas correspondentes que julgavam corretas.

A discussão de artigos científicos foi a atividade que apareceu em menor quantidade nos trabalhos analisados, apenas 6 autores $9,12,24,26,28,29$ propuseram a discussão dos artigos em pequenos grupos ${ }^{24,26}$ ou com a sala inteira. ${ }^{9,12,28,29}$ Almeida e Liotta, ${ }^{26}$ após a apresentação de se- minários sobre artigos científicos elaborada pelos alunos, dividem a classe em pequenos grupos que compartilham o mesmo interesse. Os grupos assim constituídos trabalham durante 5 semanas lendo e discutindo artigos sobre um determinado tema. Nas propostas de French, ${ }^{12}$ Duncan e Johnson ${ }^{28}$ e Bowyer e Kaydos ${ }^{29}$ os alunos preparam apresentações orais sobre o artigo e o professor, em seguida, desenvolve estratégias para promover a discussão sobre o assunto em pauta com toda a sala: uma semana antes da apresentação os alunos distribuem uma cópia do artigo e uma pequena bibliografia ou questões sobre o tema a ser apresentado.

A apresentação do artigo na forma oral foi enfatizada em 12 trabalhos. ${ }^{6,9,12,13,15,24-26,28,29,31,34}$ Em todas as propostas que constam nesses trabalhos é solicitada ao aluno a apresentação oral do conteúdo do artigo. O período destinado à apresentação varia de $10 \min ^{25}$ a 45 min..$^{29} \mathrm{~A}$ forma de apresentação do conteúdo dos artigos, na maioria dos casos, é decidida pelo aluno, que pode optar por utilizar softwares de apresentação, como o Power Point ${ }^{\circledR}$, ou qualquer outro recurso audiovisual. Dentre essas propostas, merece destaque a de Henderson e Buising, ${ }^{34}$ que foi a única a sugerir a apresentação do conteúdo dos artigos científicos na forma de painéis.

A elaboração de textos sobre os artigos foi a atividade mais freqüentemente sugerida nas propostas de ensino. De fato, em 21 delas os professores solicitaram aos estudantes a produção de material escrito. ${ }^{6,79-11,13,14,16,20,21,24-27,29-35}$ No entanto, existe uma grande diversidade quanto ao tipo de texto solicitado, sendo os mais recorrentes: resumos, textos de revisão, relatórios de laboratório no formato de artigo científico e trabalhos finais de disciplinas.

Gallagher e Adams ${ }^{14}$ solicitaram que os alunos escolhessem um artigo sobre Química Orgânica e, posteriormente, produzissem um texto, que evidenciasse a compreensão do conteúdo. De forma semelhante, White III $^{33}$ além de solicitar a produção de texto, também pediu que os alunos, divididos em grupos, produzissem um mapa conceitual sobre o artigo científico. Esse mapa foi corrigido pelos outros grupos e depois foi reformulado pelo grupo original.

Goodman e Bean, ${ }^{11}$ Baldwin ${ }^{20}$ e Tilstra ${ }^{21}$ optaram pelo modelo de publicação do Journal of the American Chemical Society como o formato a ser seguido pelos alunos na elaboração de relatórios de laboratório para disciplinas experimentais. Widanski e Courtright$\mathrm{Nash}^{27}$ também trabalharam com uma disciplina experimental na qual os alunos deveriam conduzir uma pesquisa e relatar o resultado na forma de artigo; o modelo escolhido pelo professor foi o do Journal of Undergraduate Chemistry Research.

Epling e Franck ${ }^{7}$ solicitaram aos alunos a produção de um texto de revisão que descrevesse a relação entre os diferentes artigos que os alunos haviam estudado durante o período letivo. Fikes ${ }^{9}$ conduziu uma disciplina de Química Orgânica Avançada que investigou as pesquisas realizadas por 3 cientistas. $O$ trabalho final da disciplina também consistiu na produção de um texto de revisão que resumisse e comparasse o trabalho desenvolvido por cada um deles.

\section{UTILIZAÇ̃̃o DE ARTIGOS CIENTÍFICOS NA DISCIPLINA COMUNICAÇÃO E EXPRESSÃO EM LINGUAGEM CIENTÍFICA II}

Artigos científicos foram utilizados como recurso didático na disciplina Comunicação e Expressão em Linguagem Científica II, disciplina teórica de 2 créditos, oferecida para alunos matriculados no $2^{\circ}$ semestre do curso de Bacharelado em Química do IQSC, USP. Essa disciplina não trata de conteúdos específicos de Química e tem entre os seus objetivos principais a familiarização dos estudantes com a leitura e interpretação de artigos científicos. Ademais, a disciplina visa ainda a consolidação do conhecimento de tópicos abordados na disciplina que a antecede - Comunicação e Expressão em Linguagem 
Científica I - cujos principais objetivos são discutir as diversas formas de divulgação da Ciência, apresentar aos estudantes os tipos de artigos científicos e suas características peculiares, apresentar diversas fontes de informação em Ciência e propiciar discussões sobre a importância da comunicação para o profissional da área de Química. ${ }^{36,37}$ Nesse contexto, durante o $2^{\circ}$ semestre de 2004, 57 alunos matriculados na disciplina leram, discutiram e fizeram apresentações orais e em painéis sobre o conteúdo de artigos científicos. As etapas de aplicação da proposta encontram-se descritas a seguir, assim como algumas impressões e diretrizes sinalizadas pelos alunos a partir da sua aplicação.

\section{Aplicação da proposta de ensino}

Para que a proposta de ensino fosse colocada em funcionamento, fez-se necessária, inicialmente, a seleção dos artigos científicos que seriam distribuídos aos estudantes e a definição da maneira como deveriam proceder com a sua leitura e discussão. Foram considerados artigos publicados em língua portuguesa, com o número médio de 5 páginas, e que apresentassem conteúdos compatíveis com conhecimentos adquiridos pelos alunos até a conclusão do $1^{\circ}$ semestre do curso de graduação em Química. No que diz respeito à maneira como os alunos deveriam proceder com a leitura dos artigos, foram oferecidas questões, que deveriam ser solucionadas em grupo, relacionadas à forma e ao conteúdo dos artigos. Cabe esclarecer que os critérios para a escolha dos artigos e para a elaboração das questões foram estabelecidos tomando por base, principalmente, conclusões provenientes de pesquisas anteriores realizadas por autores desse manuscrito. ${ }^{6,38}$

No primeiro dia de aula os alunos foram informados que as atividades do bimestre envolveriam a leitura e a discussão de artigos científicos, a preparação de uma apresentação oral, de um painel e de um texto sobre o conteúdo dos mesmos. Na ocasião foram também formados 15 grupos (sendo 10 grupos de 4 alunos, 4 grupos de 3 alunos e 1 grupo de 5 alunos) e cada grupo recebeu a incumbência de trabalhar com um artigo científico extraído da revista Química Nova ou Eclética Química. A Tabela 2 apresenta alguns dos artigos selecionados.

Um total de $8 \mathrm{~h} /$ aula ( $2 \mathrm{~h} /$ aula por semana, durante 4 semanas), no período normal de aula, foi dedicado às atividades envolvendo os artigos científicos. Nas 3 primeiras semanas os grupos assistiram a uma aula expositiva, ministrada pelo docente responsável pela disciplina, sobre a elaboração de apresentações orais e de painéis e receberam as orien- tações para o trabalho com o artigo científico, apresentadas no Quadro 1. Além das atividades em classe, os alunos também foram incumbidos de realizar as atividades extraclasse, apresentadas no Quadro 2. Ainda nesse período, no $2^{\circ}$ dia de atividade, um dos integrantes de cada grupo se dirigiu à sala de computadores, destinada à realização de trabalho de alunos de graduação do IQSC, e recebeu orientações sobre o uso do software Power Point ${ }^{\circledast}$, que seria empregado na confecção dos painéis e dos slides que comporiam a apresentação oral.

$\mathrm{Na} 4^{\mathrm{a}}$ semana de atividades, concluída a etapa de leitura e discussão das questões pelos estudantes, algumas respostas por eles fornecidas foram reunidas e amplamente debatidas em uma aula conduzida pelo professor responsável pela disciplina.

$\mathrm{Na} 5^{\text {a }}$ semana, em horário extraclasse, foi organizado um minisimpósio em 4 sessões, no qual o conteúdo do artigo científico estudado foi apresentado por um dos membros de cada grupo em um intervalo de 15 a 20 min. A programação do mini-simpósio foi elaborada de tal forma que 3 ou 4 artigos fossem apresentados em cada sessão. Nessas sessões, além do professor responsável pela disciplina, outros docentes do IQSC assistiram e avaliaram as apresentações orais dos alunos. Ainda na $5^{\text {a }}$ semana, também em período extraclasse, durante $2 \mathrm{~h}$, os alunos fizeram as apresentações de painéis relacionados aos conteúdos dos artigos com os quais haviam trabalhado. Na ocasião, cada aluno ficou incumbido de visitar todos os painéis e propor pelo menos uma questão sobre cada trabalho exibido. A questão formulada e a resposta recebida deveriam ser anotadas e entregues ao professor ao final da atividade.

Destacamos que, embora os alunos tenham dedicado $8 \mathrm{~h}$ para as atividades realizadas no período normal de aula, um tempo considerável foi utilizado por eles em atividades extraclasse, que envolveram: buscas por informações para resolução das tarefas extraclasse, preparação e apresentação dos painéis, preparação do texto escrito, preparação da apresentação oral e participação no mini-simpósio.

\section{Considerações sobre a proposta de ensino: possibilidades e limitações}

As atividades realizadas exigiram o cumprimento de etapas capazes de acentuar: o interesse dos alunos pela aprendizagem de conteúdos específicos de Química; a capacidade de comunicação em linguagem científica; a familiarização com os artigos (localização, reconhecimento de características, leitura crítica e compreensão); o entendimento sobre o processo de construção da Ciência. Os ele-

Tabela 2. Alguns dos artigos utilizados como recurso didático na disciplina Comunicação e Expressão em Linguagem Científica II

Artigo e autor(es) Revista, ano, volume, página inicial

Avaliando a contaminação por elementos traço em atividades de maricultura.

Resultados parciais de um estudo de caso realizado na Ilha de Santa Catarina, Brasil

Química Nova 2003, 26, 44

Curtius, A. J.; Seibert, E. L.; Fiedler, H. D.; Ferreira, J. F.; Vieira, P.H.F.

Caracterização e classificação do resíduo sólido "pó balão" gerado na indústria siderúrgica

não integrada a carvão vegetal: - estudo de um caso na região de Sete Lagoas/MG

Oliveira, M. R. C.; Martins, J.

Química Nova 2003, 26, 5

Propagação da poluição atmosférica por flúor nas águas subterrâneas e solos de regiões próximas às indústrias de fertilizantes (Rio Grande, RS)

Química Nova 2002, 25, 191

Mirlean, N.; Casartelli, M. R.; Garcia, M. R. D.

Exposição ocupacional a compostos orgânicos voláteis na indústria naval Costa, M. F. B.; Costa, M. A. F.

Química Nova 2002, 25, 384

Avaliação de poluição do ar por chumbo particulado: uma abordagem geoquímica Vanz, A.; Mirlean, N.; Baisch, P.

Química Nova 2003, 26, 25

Geoquímica e índice de geoacumulação de mercúrio em sedimentos de superfície do estuário de Santos - Cubatão (SP)

Luiz-Silva, W.; Matos, R. H. R.; Kristosch, G. C.

Química Nova 2002, 25, 753 
Quadro 1. Questões solucionadas pelos alunos sobre os artigos científicos (atividade em sala)

\section{ATIVIDADE I}

\section{A - FAZENDO O RECONHECIMENTO DO ARTIGO}

1. Título do artigo; 2. Autores do artigo; 3. Autor principal do artigo; 4. Instituições a que pertencem os autores do trabalho; 5. Citem a(s) agência(s) que forneceu(ram) auxílio financeiro ao trabalho.

\section{B - PENSANDO SOBRE SUAS RESPOSTAS}

1. Qual critério foi escolhido por vocês para indicar o autor principal do artigo? O que faz com que ele ocupe essa posição?

2. Se o trabalho desenvolvido no artigo foi realizado através da interação entre diferentes universidades e/ou institutos de pesquisa, por que vocês imaginam que as interações são necessárias?

3. Vocês conhecem a(s) agência(s) de fomento citada(s) no artigo? Como vocês imaginam que as agências distribuem as suas verbas para os pesquisadores?

\section{C - COLOCANDO A MÃO NA MASSA I}

1. Todos os membros do grupo devem fazer a leitura do título do artigo. Um dos membros se responsabiliza por coordenar um brainstorming. Este membro deve fazer anotações sobre os resultados obtidos com esse procedimento.

2. Cada um dos membros do grupo faz a leitura da introdução do artigo e sublinha todas as palavras cujo significado não é conhecido. O membro do grupo que coordenou o brainstorming deve anotar todas as palavras/expressões assinaladas por todos os outros colegas. Discutir as palavras grifadas e, por meio de troca de informações entre os membros, tentar compreender o significados das mesmas.

3. Repitam o procedimento adotado na resolução da questão anterior, lendo agora a parte sobre materiais e métodos do artigo.

4. Quais foram as substâncias químicas utilizadas no trabalho? Por que essas substâncias foram escolhidas?

5. Quais foram os materiais e as técnicas químicas mencionadas no artigo? Selecionem os materiais que vocês já conhecem e expliquem as suas funções e, no caso das técnicas, expliquem os seus princípios.

\section{D - COLOCANDO A MÃO NA MASSA II}

6. Cada um dos membros do grupo faz a leitura das seções finais do artigo e sublinha todas as palavras cujo significado não é conhecido. O membro do grupo que coordenou o brainstorming deve anotar todas as palavras/expressões assinaladas por todos os outros colegas. Discutir as palavras grifadas e, por meio de troca de informações entre os membros, tentar compreender o significados das mesmas.

7. Na opinião de vocês, qual(is) o(s) principal(is) problema(s) que os autores do artigo se propuseram a solucionar?

8. Como vocês acreditam que os pesquisadores, em geral, escolhem os seus problemas de pesquisa?

9. Os autores solucionaram o(s) problema(s) com os quais haviam se deparado inicialmente? Justifiquem as suas respostas, apresentando fatores decisivos que contribuíram para a solução (ou não) do(s) problema(s).

Quadro 2. Questões solucionadas pelos alunos sobre os artigos científicos (atividades extraclasses)

\section{ATIVIDADE EXTRACLASSE I}

1. Apresentem uma breve descrição das técnicas empregadas no artigo.

2. Mostrem as estruturas e algumas propriedades das principais substâncias químicas utilizadas no artigo e relatem a função de cada uma delas no trabalho.

3. Apresentem os significados das palavras que vocês grifaram durante o trabalho realizado em sala.

4. Utilizando recursos de buscas de artigos científicos já conhecidos por vocês (Web of Science, Chemical Abstracts e Currículo Lattes) localizem trabalhos relacionados ao artigo que vocês têm em mãos que tenham sido publicados pelos autores. Façam cópias e anexem à folha de respostas pelo menos 2 dos artigos localizados.

\section{ATIVIDADE EXTRACLASSE II}

1. Apresentem os significados das palavras que vocês grifaram durante o trabalho realizado em sala.

2. Utilizando recursos de buscas de artigos científicos já conhecidos por vocês (Web of Science, Chemical Abstracts e Currículo Lattes) localizem trabalhos relacionados ao assunto tratado no artigo que vocês têm em mãos. Façam cópias e anexem à folha de respostas pelo menos 2 artigos localizados. Justifiquem a escolha dos artigos, ou seja, no que eles se assemelham ao artigo trabalhado em sala.

3. Apresentem uma análise dos principais gráficos, tabelas e figuras existentes no artigo. Ou seja, qual a sua importância para o entendimento do trabalho e o que eles significam (em termos de conteúdo de química). Façam este exercício pelo menos 3 vezes.

4. A partir da leitura de seu artigo e daqueles a ele relacionados (buscas realizadas extraclasse), considere: a) qual a importância da pesquisa para a sociedade? b) quais são as suas possíveis aplicações? c) cite outras abordagens dadas ao assunto tratado no artigo por outros pesquisadores. Façam comentários sobre essas abordagens, comparando-as com aquela utilizada pelo autor do texto utilizado em sala.

5. As referências bibliográficas citadas no artigo sustentam as informações nele contidas? De que forma? Para explicar melhor essa questão, utilizem um exemplo. 
mentos relacionados a cada uma das etapas capazes de promover o favorecimento dos aspectos mencionados são discutidos a seguir.

Embora o ensino e a aprendizagem de conteúdos de Química não fosse o objetivo principal da proposta, a leitura e a compreensão dos artigos envolveram, necessariamente, o estudo de alguns conceitos de Química. Assim, as seguintes solicitações e questões propostas aos estudantes se mostraram como potenciais para despertar o interesse dos alunos pelo aprendizado de conteúdos específicos: quais foram as substâncias químicas utilizadas no trabalho? por que essas substâncias foram escolhidas? quais foram os materiais e as técnicas mencionadas no artigo? selecionem os materiais que vocês já conhecem e expliquem as suas funções e, no caso das técnicas, expliquem os seus princípios; mostrem as estruturas e algumas propriedades das principais substâncias químicas utilizadas no artigo e relatem a função de cada uma delas no trabalho; apresentem uma análise dos principais gráficos, tabelas e figuras existentes no artigo.

Dentre as etapas da proposta que se mostraram como potenciais para o aperfeiçoamento de habilidades de comunicação oral e escrita em linguagem científica dos alunos, estão a elaboração e apresentação do conteúdo do artigo na forma oral e de painel.

Com relação à familiarização com os artigos científicos, as etapas da proposta que exigiram dos alunos a localização dos artigos com os quais trabalhariam e a resolução para questões, como a apresentada a seguir, mostraram-se como potenciais para o desenvolvimento dessa habilidade: utilizando recursos de buscas de artigos científicos já conhecidos por vocês (Web of Science, Chemical Abstracts e Currículo Lattes) localizem trabalhos relacionados ao assunto tratado no artigo que vocês têm em mãos. Façam cópias e anexem à folha de respostas pelo menos 2 artigos localizados. Justifiquem a escolha dos artigos, ou seja, expliquem no que eles se assemelham ao artigo trabalhado em sala.

Nessa perspectiva, os seguintes questionamentos também se mostraram como potenciais para a familiarização dos alunos com o formato e o conteúdo do artigo, favorecendo a interpretação dos dados nele discutidos: as referências bibliográficas citadas no artigo sustentam as informações nele contidas? de que forma? para explicar melhor essa questão, utilizem um exemplo; os autores solucionaram $\mathrm{o}(\mathrm{s})$ problema(s) com o(s) qual(is) haviam se deparado inicialmente? Justifiquem as suas respostas, apresentando fatores decisivos que contribuíram para a solução (ou não) do(s) problema(s).

As etapas da proposta que se mostraram como potenciais para o desenvolvimento do entendimento sobre o processo de construção do conhecimento científico trataram de colocar aos estudantes questionamentos, como os apresentados a seguir, que fomentam discussões a respeito da temática: se o trabalho desenvolvido no artigo foi realizado através da interação entre diferentes universidades e/ou institutos de pesquisa, por que vocês imaginam que as interações são necessárias? Vocês conhecem a(s) agência(s) de fomento citada(s) no artigo? Como vocês imaginam que as agências distribuem as suas verbas para os pesquisadores? Como vocês acreditam que os pesquisadores, em geral, escolhem os seus problemas de pesquisa?

No que diz respeito às limitações da proposta, destacamos as dificuldades que podem ser enfrentadas pelos docentes com a sua aplicação em turmas numerosas. Uma turma que proporcione a for- mação de muitos grupos de alunos, seguramente, exigirá um esforço considerável por parte do professor na correção de uma quantidade elevada de tarefas e na coordenação do trabalho em sala de aula.

Outra limitação da proposta diz respeito às condições necessárias para a sua plena aplicação: o acesso a uma ampla gama de periódicos e livros relacionados à área de Química e a computadores, necessários para a confecção de painéis e de slides para apresentação oral, é indispensável.

\section{Impressões dos alunos sobre a proposta de ensino}

Ao final do bimestre, solicitamos aos alunos que apresentassem, a partir da resolução do questionário apresentado no Quadro 3, suas impressões sobre a relevância (ou não) das atividades realizadas e possíveis sugestões para o aprimoramento da proposta de ensino, sem que se identificassem. Também os questionamos sobre o interesse em participar de uma disciplina de formato e objetivos semelhantes, em nível mais avançado, em semestres posteriores do curso de Bacharelado. Dentre os 57 alunos matriculados na disciplina, 52 compareceram à aula na qual o questionário foi aplicado. As respostas por eles oferecidas são discutidas na Tabela 3.

Com relação ao primeiro questionamento, verificamos a existência de consenso, praticamente geral, entre os estudantes sobre a relevância da proposta, uma vez que somente 1 aluno respondeu negativamente à questão. As justificativas mais freqüentemente citadas para tal relevância foram agrupadas nas seguintes categorias: suporte para atividades realizadas ao longo do curso de Bacharelado; suporte para a realização de comunicações científicas (orais e escritas); suporte para a vida profissional, como químico; suporte para aqueles alunos que seguirão a carreira acadêmica; reforço e estímulo à leitura. Em cada produção escrita foram, então, demarcados os trechos que correspondiam a uma determinada categoria, de tal forma que foi possível identificar, em alguns trechos, mais de uma categoria em uma mesma resposta. Por esta razão, o número de respostas apresentado na Tabela 3 é 56 e não 52, como esperado a partir do número de alunos que respondeu o questionário. Em seguida, cada categoria foi contabilizada e analisada, juntamente com os recortes extraídos das respostas dos alunos. Todos os percentuais apresentados na Tabela 3 foram calculados sobre 56 justificativas.

A Tabela 3 indica a distribuição das respostas dos alunos sobre as razões que justificam a relevância da proposta. Majoritariamente, as respostas convergiram para a relevância da proposta tendo em vista o suporte que oferece para a vida profissional $(41,0 \%)$. Em geral, as respostas agrupadas nesta categoria mostravam explicitamente tal constatação, como sugere o excerto:

"Um bom profissional em química, ao meu ver, deve não só ser um bom pesquisador, mas um bom expositor de suas pesquisas. Um bom professor de química aumentará a qualidade de suas aulas se souber expor com clareza os conceitos que pretende ensinar. Portanto, considero esta atividade fundamental para minha vida profissional".

Embora as considerações dos alunos tenham se concentrado na

Quadro 3. Questionário aplicado aos alunos com o intuito de conhecer suas impressões a respeito da proposta de ensino

1. Durante o primeiro bimestre você realizou atividades em grupo que trataram da leitura e interpretação de um artigo científico e da produção de um texto escrito, de um painel e de uma apresentação oral a respeito do mesmo. Nessa perspectiva:

a) Qual a relevância (ou não) do referido processo para a sua formação profissional? Justifique sua resposta.

b) Quais sugestões você poderia apresentar para o aperfeiçoamento da proposta de ensino, que visou o aprimoramento da capacidade de leitura e interpretação de textos científicos e de habilidades de expressão em linguagem científica?

c) Qual a sua opinião sobre a realização de um curso no mesmo formato, em nível mais avançado, em semestres posteriores? 
Tabela 3. Distribuição das justificativas apresentadas pelos alunos para a relevância da proposta de ensino aplicada

\begin{tabular}{lll}
\hline Justificativas apresentadas pelos alunos para a relevância da proposta & $\mathrm{N}^{\mathrm{o}}$ & $(\%)$ \\
\hline Suporte para a vida profissional, como químico. & 23 & 41,0 \\
Suporte para aqueles alunos que seguirão a carreira acadêmica. & 12 & 21,4 \\
Suporte para atividades realizadas no curso de Bacharelado. & 10 & 17,9 \\
Suporte para a realização de comunicações científicas (orais e escritas). & 10 & 17,9 \\
Reforço e estímulo à leitura. & 1,8 \\
\hline
\end{tabular}

vida profissional, de forma geral, uma parte considerável associou as atividades propostas na disciplina com trabalhos que terão que realizar no decorrer do curso de graduação $(17,9 \%)$ e caso desejem seguir a carreira acadêmica $(21,4 \%)$.

Percepções quanto à importância da atividade como suporte para a realização de comunicações científicas também foram observadas com freqüência razoável $(17,9 \%)$, enquanto um único aluno destacou a sua importância como reforço e estímulo à leitura $(1,8 \%)$, conforme ilustra o excerto:

"A principal relevância consiste no fato de que o entendimento da leitura é fundamental para qualquer área do conhecimento e o que fizemos aqui reforça e estimula este entendimento".

No que diz respeito às sugestões apresentadas para o aperfeiçoamento da proposta, 19 alunos não apontaram nenhuma indicação de mudança, tendo 9 deles justificado a ausência de sugestões com base na aprovação com relação à mesma, conforme ilustram os excertos:

“Na minha opinião, a forma ideal de ensino desta disciplina é a forma atual, principalmente quanto à realização de trabalhos em grupo. Dessa forma, se algum integrante tem alguma dificuldade, os outros podem ajudá-lo a sanar essa dificuldade, acentuando, assim, o processo de aprendizado”.

"Não tenho sugestões. Acho que a estratégia de ensino está muito boa e não precisa ser mudada”.

Dentre as sugestões apresentadas pelos demais alunos destacamse as seguintes: apresentação oral do artigo científico por todos os membros do grupo e não somente por um, como no formato atual da proposta (sugestão apresentada por 8 alunos); escolha do artigo científico a ser apresentado pelos membros do grupo e não pelo docente da disciplina, como no formato atual da proposta (sugestão apresentada por 4 alunos); organização de aulas nas quais os alunos possam assistir a seminários ministrados por professores ou por alunos de pós-graduação (sugestão apresentada por 3 alunos). Outras sugestões, expressas com menor freqüência, foram: maior tempo para a realização das atividades; menor quantidade de atividades extraclasse; oferecimento de artigos ainda mais fáceis de serem compreendidos; acompanhamento mais efetivo durante a preparação das apresentações orais.

No que diz respeito ao interesse dos alunos na participação de um curso de natureza semelhante em semestres posteriores, 33 alunos responderam positivamente, 4 alunos não responderam ao questionamento, 6 afirmaram não estar seguros a respeito e 9 responderam negativamente. $\mathrm{O}$ fato da maioria dos alunos ter se mostrado favorável a este questionamento sugere a boa receptividade que disciplinas voltadas à discussão de questões sobre a comunicação científica podem vir a ter em cursos de Química no nível superior.
Nessa perspectiva, considerações sobre a importância creditada à comunicação científica por alunos matriculados nestes cursos foram feitas por Oliveira e Queiroz. ${ }^{39}$

\section{CONSIDERAÇÕES FINAIS}

Neste trabalho apresentamos algumas características, possibilidades e limitações do emprego de artigos científicos como recurso didático no ensino superior de Química. Consideramos, a partir da análise do conjunto de trabalhos relacionados ao assunto, que propostas de ensino pautadas na utilização de artigos científicos podem trazer elementos para as salas de aula e para os laboratórios de ensino capazes de fomentar o desenvolvimento de habilidades pouco privilegiadas na formação dos graduandos de Química, e destacadas como de fundamental importância nas Diretrizes Curriculares Nacionais para os Cursos de Química. ${ }^{5}$ Assim, julgamos pertinente a divulgação de iniciativas dessa natureza e acreditamos que os professores de Química, interessados em fazer uso de artigos científicos em ambientes de ensino, encontrarão no presente manuscrito subsídios para tanto.

\section{AGRADECIMENTOS}

À FAPESP (Processo 03/06107-0) e ao CNPq (Processo 306077/2006-0) pelo suporte financeiro e aos alunos matriculados na disciplina Comunicação e Expressão em Linguagem Científica II (IQSC-USP) no $2^{\circ}$ semestre de 2004.

\section{REFERÊNCIAS}

1. Queiroz, S. L.; Quim. Nova 2001, 24, 143.

2. Campanario, J. M.; Enseñanza de las Ciencias 2004, 22, 365.

3. Sá, L. P.; Francisco, C. A.; Queiroz, S. L.; Quim. Nova 2007, 30, 731.

4. Lemke, J. L.; Talking Science, Ablex Publishing: Westport, 1990.

5. Zucco, C.; Pessine, F. B. T.; de Andrade, J. B.; Quim. Nova 1999, 22, 454.

6. Santos, G. R.; Sá, L. P.; Queiroz, S. L.; Quim. Nova 2006, 29, 1121.

7. Epling, G. A.; Franck, R. W.; J. Chem. Educ. 1979, 56, 388.

8. Wubbels, G. G.; J. Chem. Educ. 1972, 49, 496.

9. Fikes, L. E.; J. Chem. Educ. 1989, 66, 920.

10. Thoman, C. J.; J. Chem. Educ. 1989, 63, 859.

11. Goodman, W. D.; Bean, J. C.; J. Chem. Educ. 1983, 60, 483

12. French, L. G.; J. Chem. Educ. 1992, 69, 287

13. Rossi, F. M.; J. Chem. Educ. 1997, 74, 395.

14. Gallagher, G. J.; Adams, D. L.; J. Chem. Educ. 2002, 79, 1368.

15. Rosenstein, I. J.; J. Chem. Educ. 2005, 82, 652.

16. Sherman, L. R.; J. Chem. Educ. 1988, 65, 993.

17. Cornely, K.; J. Chem. Educ. 1998, 75, 475.

18. O' Malley, R. F.; J. Chem. Educ. 1964, 41, 512

19. Burness, J. H.; J. Chem. Educ. 1996, 73, 1120.

20. Baldwin, M. J.; J. Chem. Educ. 2003, 80, 307.

21. Tilstra, L.; J. Chem. Educ. 2001, 78, 762

22. Parker, G. A.; J. Chem. Educ. 1973, 50, 606. 
23. Roecker, L.; J. Chem. Educ. 2007, 84, 1380.

24. Drake, B. D.; Acosta, G. M.; Smith Jr., R. L.; J. Chem. Educ. 1993, 70, 462.

25. Whelan, R. J.; Zare, R. N.; J. Chem. Educ. 2003, 80, 904.

26. Almeida, C. A.; Liotta, L.J .; J. Chem. Educ. 2005, 82, 1794.

27. Widanski, B. B.; Coourtright-Nash, D.; J. Chem. Educ. 2006, 83, 1788 .

28. Duncan, A. P.; Johnson, A. R.; J. Chem. Educ. 2007, 84, 443.

29. Bowyer, W.J.; Kaydos, J.A.; J. Chem. Educ. 1997, 74, 184.

30. Paulson, D. R.; J. Chem. Educ. 2001, 78, 1047.

31. Schildcrout, S. M.; J. Chem. Educ. 2002, 79, 1340.
32. Melhado, L.; J. Coll. Sci. Teach. 1981, 11, 299.

33. White III, H. B.; J. Coll. Sci. Teach. 2001, 31, 106

34. Henderson. L.; Buising, C.; J. Coll. Sci. Teach. 2001, 30, 109.

35. Garrat, J.; Overton, T.; Educ. Chem. 1996, 137.

36. Oliveira, J. R. S.; Queiroz, S. L.; Atas do V Encontro Nacional de Pesquisa em Educação em Ciências, Bauru, Brasil, 2005.

37. Oliveira, J. R. S.; Queiroz, S. L.; Comunicação e Linguagem Científica: Guia para Estudantes de Química, Editora Átomo: Campinas, 2007.

38. Santos, G. R.; Sá, L. P.; Queiroz, S. L.; Atas do V Encontro Nacional de Pesquisa em Educação em Ciências, Bauru, Brasil, 2005.

39. Oliveira, J. R. S.; Queiroz, S. L.; Quim. Nova 2008, 31, 1263. 